\title{
LAJES ESTRUTURAIS COM UTILIZAÇÃO DE GARRAFAS DE POLIETILENO (PET)
}

Gabriela Alves de Lima Cardoso ${ }^{1}$; Ivair Salomão Liboni ${ }^{2}$; Sibila Corral de Arêa Leão Honda ${ }^{3}$

Universidade do Oeste Paulista - UNOESTE, Faculdade de Engenharias e Arquitetura e Urbanismo, Presidente Prudente, SP. E-mail: engenheiragabrielalima@hotmail; ivair@unoeste.br; sibila@unoeste.br.

\section{RESUMO -}

As garrafas de Polietileno Tereftalato (PET) são largamente utilizadas no mundo, seja por facilidade de design, por durabilidade ou por facilidade de manuseio, transporte e estocagem. No entanto, problemas de logística reversa onde a embalagem em pós-uso, por não ter uma destinação final adequada, acarreta em poluição ao meio ambiente. Visando à retirada deste material do meio ambiente de forma ecologicamente responsável, associada à redução de custo de produção e de peso próprio de lajes nervuradas de concreto, este artigo vem a discutir pesquisa elaborada por meio de análise laboratorial e de viabilidade de construção de lajes com a utilização de garrafas PET em seu interior. Verificaram-se aspectos positivos, econômicos, técnicos e ambientais.

Palavras-chave: Polietileno; concreto armado; laje estrutural; laje nervurada; reaproveitamento.

\section{STRUCTURAL SLABS WITH USE OF POLYETHYLENE BOTTLES (PET)}

ABSTRACT - Polyethylene bottles (PET) have been widely used in the world nowadays, whether by easily design, durability or ease of handling, transportation and storage. However, reverse logistics problems due to lack of proper disposal of packaging causes pollution to the environment. Seeking the removal of this material from an ecologically responsible manner environment, associated with the reduction of production costs and the own weight concrete waffle slabs, this paper has the objective of discuss a research carried out by laboratory analysis and slabs construction feasibility, which slabs were built with PET use inside. Positive features were verified, as economic, echnical and environmental.

Keywords: Polyethylene; paving stone; structural slab; waffle slab; reutilization 


\section{INTRODUÇÃO}

Devido às crescentes imposições arquitetônicas há uma busca de alternativa no processo construtivo que são direcionados para no mesmo objetivo aliar segurança e economia. Dentro deste contexto, as lajes nervuradas surgiram como uma excelente alternativa na construção de pavimentos em edificações, pois são capazes de alcançar grandes vãos com altos índices de produtividade, versatilidade e, principalmente, reduzindo o peso próprio e o custo do sistema.

De acordo com a norma da ABNT NBR 6118:2007, as lajes são elementos de superfície plana sujeitos a ações normais em seu plano, sendo que as placas de concreto são usualmente denominadas lajes. Segundo Botelho e Marchetti (2007), chamam-se lajes pré-moldadas de concreto armado o conjunto de vigotas de concreto armado e blocos de enchimento, fornecido por empresa de lajes e capa de concreto e aço colocada na obra pelo construtor.

Analisando as funcionalidades e materiais utilizados na confecção de lajes nervuradas e unindo ao pensamento sustentável, vertente crescente na construção civil, esta pesquisa objetivou analisar a viabilização da utilização de garrafas de Polietileno Tereftalato (PET) na fabricação de Lajes de alta capacidade de carga, com o intuito de diminuição de peso próprio, visto que as garrafas ocupam o espaço antes utilizado por concreto ou bloco cerâmico, retirada do material reciclado do meio ambiente (PET) e evitando a produção de material poluidor; e possibilidade de diminuição de custo de execução de uma laje de tal porte, para que este modelo construtivo tenha posição competitiva no mercado.

O Poli (Polietileno Tereftalato ou Tereftalato de Etileno), ou, simplesmente PET, é um polímero termoplástico da família dos poliésteres. Embora amplamente utilizado na indústria de garrafas plásticas, a PET iniciou sua história na indústria têxtil. A primeira amostra da resina foi desenvolvida pelos ingleses Whinfield e Dickson, em 1941. A ideia era criar alternativas viáveis para as fibras até então usadas, cujos campos estavam destruídos pela guerra. $O$ poliéster apresentou-se como um excelente substituto para o algodão - função que cumpre muito bem até hoje, inclusive a partir das garrafas recicladas (CASSIMINHO, 1999).

Segundo a ABIPET (Associação Brasileira da Industria PET, s/d): o PET é o plástico mais resistente e o melhor para fabricação de garrafas, frascos e embalagens para bebidas e óleos para consumo humano, medicamentos, cosméticos, produtos de higiene e limpeza, entre vários outros. O PET proporciona alta resistência mecânica (impacto) e química, suportando o contato com agentes agressivos.

\section{METODOLOGIA}

\section{Materiais}

Para execução de testes de compressão foram fabricados 2 protótipos de 1,10 $\mathrm{m} \times 1,10 \mathrm{~m}$ cada. Para execução de tais protótipos foram utilizados:

- Tela em aço CA-50 $4 \mathrm{~mm}$

- Madeira para fôrma de $20 \mathrm{~cm}$ de largura (tabuas de $3 \mathrm{~m}$ )

- Areia

-Cimento

-Lona

-Água

-Brita

- Arame recozido

- Pregos

-Garrafas PET 2 litros

\section{Montagem dos protótipos}

Fôrmas - Foram executadas duas fôrmas em madeira Pinnus, com tábuas de 0,20 m de altura, com dimensões de 1,10 m x 1,10 m. Abaixo das formas foi colocada lona plástica para que o protótipo não aderisse ao concreto do pavimento durante tempo de cura.

Aço - Para execução de concreto armado, foi inserido, de ambos os lados da PET uma tela de aço $4 \mathrm{~mm}$ com dimensões de $1 \mathrm{~m} \times 1 \mathrm{~m}$ e amarradas às garrafas PET com arame recozido para 
facilitar a montagem e concretagem. Na parte inferior da laje, foi colocado calços de 0,02 $\mathrm{m}$ para obtenção de cobrimento de concreto na parte inferior a armação.

PET - Para cada protótipo foram utilizadas 30 Garrafas PET de 2 litros de volume, devidamente limpas e tampadas. As garrafas foram amarradas à armação superior com utilização de arame recozido, enfileiradas em grupos de 10 unidades, todas no mesmo sentido, com o mínimo de espaço possível entre elas. Após a amarração, foram dispostas dentro da forma de modo centralizado.

Concreto - Para execução do concreto foi utilizado traço 3:2:1 com utilização de baldes como unidades de medida. $O$ concreto foi executado em Betoneira, sendo necessários 2 volumes completos de betoneira para concretagem de cada unidade de protótipo. Foram executados 0,02 $\mathrm{m}$ de cobertura na parte inferior e $0,05 \mathrm{~m}$ de cobertura na parte superior da armadura, totalizando $17 \mathrm{~cm}(0,02 \mathrm{~m}$ de cobertura inferior $+0,10 \mathrm{~m}$ da espessura da garrafa PET $+0,05 \mathrm{~m}$ de cobertura superior) de espessura de laje. 0 tempo de cura de ambos os protótipos foi de 21 dias. Sendo os protótipos rompidos após 38 dias de concretados.

Teste de compressão - $O$ teste de compressão foi executado em uma Mesa de Reações, no laboratório de construção civil da Universidade do Oeste Paulista. Para apoio da laje foram utilizados 4 apoios de mármore e 2 vigotas de madeira. As vigas de transferência de Carga foram apoiadas em cima de 2 vigas metálicas sobrepostas a 4 placas metálicas, com um pino para a transferência das cargas em 2 pontos estipulados no centro da laje. As vigas de transferência possuem 2,83 $\mathrm{m}$ de comprimento, sendo o apoio em pino, fixado a 0,15 $\mathrm{m}$ de distância do Eixo base (viga transversal de apoio). Na outra extremidade das vigas foi apoiado o suporte para colocação dos pesos.

\section{RESULTADOS}

\section{Protótipo 1}

Para rompimento de estrutura de concreto armado do protótipo 1 foram colocados em cada apoio da viga de transferência da Mesa de Reações 9 unidades de peso, totalizando 18 pesos. Os pesos possuem peso próprio de $15 \mathrm{~kg}$ cada um, totalizando $270 \mathrm{~kg}$ de peso adicionado ao sistema inicial.

\section{Prototipo 2}

Para rompimento de estrutura de concreto armado do protótipo 1 foram colocados em cada apoio da viga de transferência da Mesa de Reações 8 unidades de peso, totalizando 16 pesos. Os pesos possuem peso próprio de $15 \mathrm{~kg}$ cada um, totalizando $240 \mathrm{~kg}$ de peso adicionado ao sistema inicial.

\section{DISCUSSÃO}

\section{Sistema de forças Binário}

Denomina-se binário o sistema constituído por um par de forças paralelas, de módulos iguais e sentidos opostos. A resultante em termo de forças é nula, entretanto há um momento polar resultante de módulo igual ao produto da força pela distância entre as duas direções paralelas.

Considerando a barra de transferência de forças com comprimento de 2,83 $\mathrm{m}$ e o pino de transferência de forças à laje, localizado $0,15 \mathrm{~cm}$ à esquerda do apoio na viga transversal, tem-se um sistema de alavancas onde, o peso adicionado à barra de transferência de forças gera, devido à equação de Momento Fletor (Mf), um momento especifico no pino de transferência de cargas.

$$
\mathrm{Mf}=\mathrm{F} . \mathrm{d}=270.2,68=723,6 \mathrm{kgf} . \mathrm{m}
$$


Sabe-se que devido à utilização da barra de transferências, deve-se adicionar ao Momento Fletor total o Momento fletor do peso próprio da barra de transferência no ponto 0,15 $\mathrm{m}$, resultando:

$$
\text { Mf }(\text { total })=\text { Mf }+ \text { Pviga }=723,6+133,28=856,88 \mathrm{kgf} . \mathrm{m}
$$

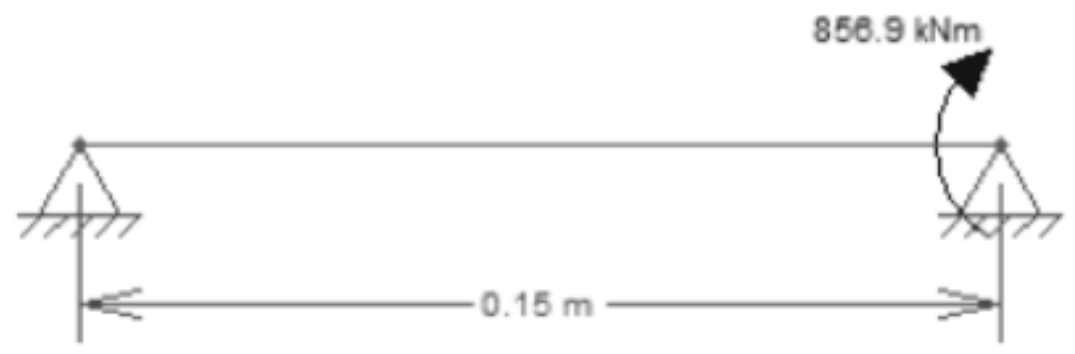

Considerando-se a resultante das forças um sistema binário, onde as forças resultantes RA e RB (nas extremidades de apoio da barra de transferência de cargas, sendo um apoio no ponto de apoio com a viga transversal e o outro ponto de apoio a 0,15 $\mathrm{m}$ de distância no pino de transferência de cargas para Laje.

$$
R A=R B=M / I=856,88 / 0,15=5712,7 \mathrm{kgf}
$$

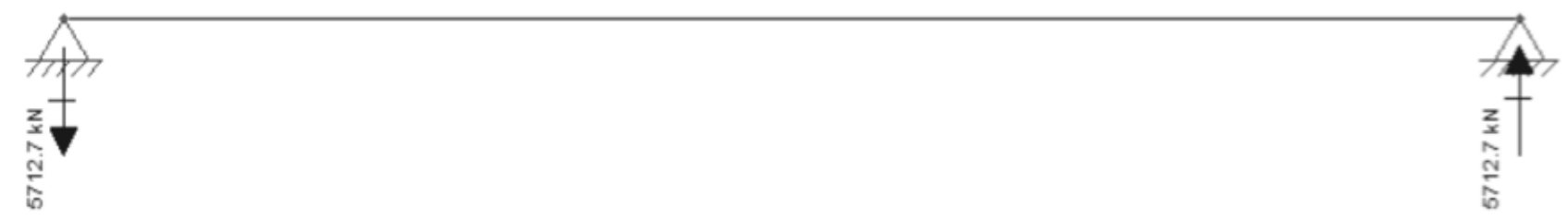

Sabe-se então que a força total transferida para a laje é de 5712,7 kgf, sendo este divididos em dois pontos de carga localizados a 0,21 m de distância um do outro:

Carga por ponto na laje $=2856 \mathrm{kgf}$

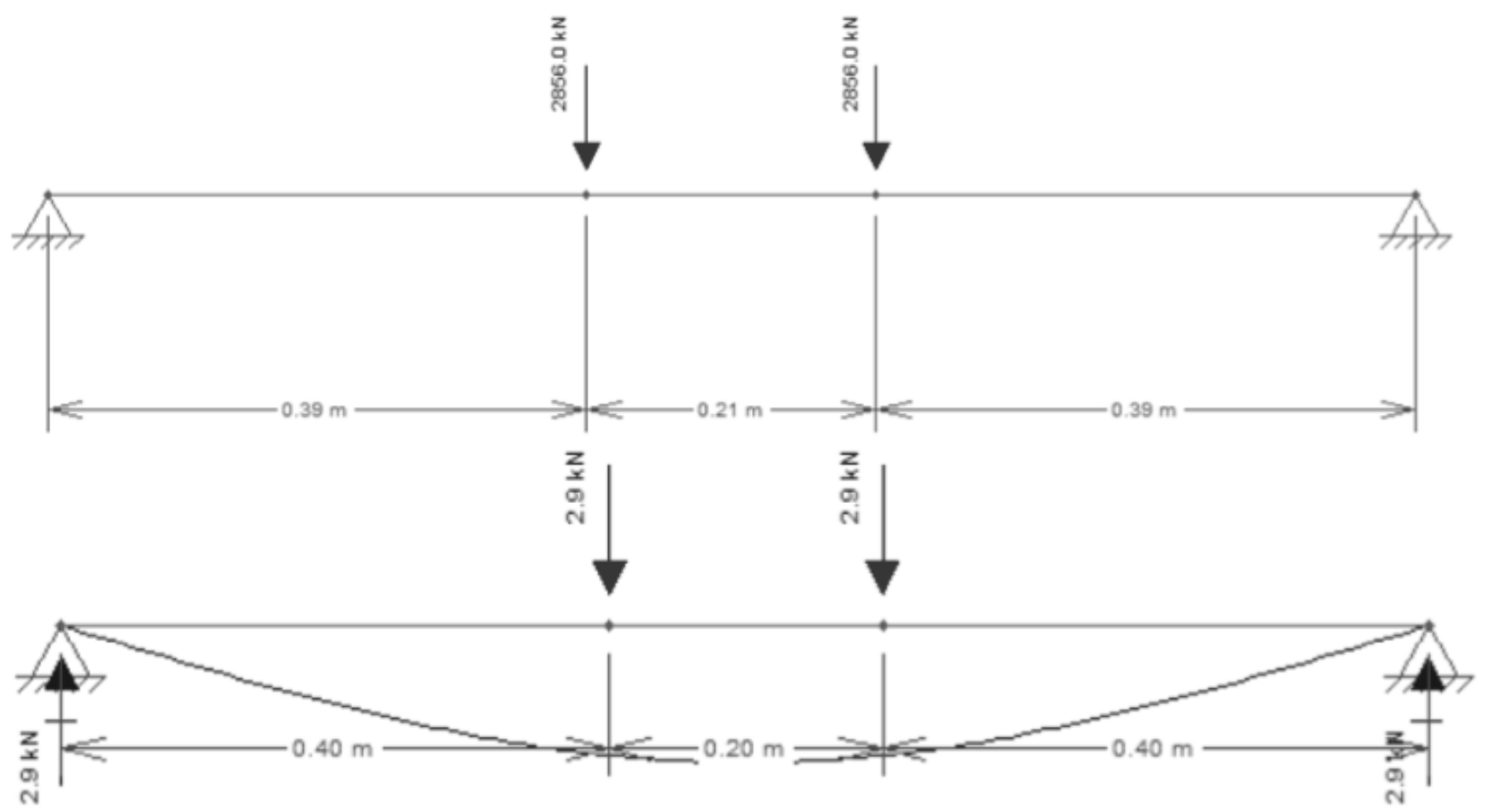

\section{CONCLUSÃO}

Considerando o intuito de desenvolver um método construtivo eficaz, com redução de peso próprio, seguro, sustentável e de menor custo possível, pode-se concluir: 


\section{Método Construtivo}

De acordo com o procedimento detalhado neste trabalho, utilizando-se de forma simples, clara e objetiva, o método construtivo descrito visa a construção de uma laje de modo seguro e prático, onde o sistema PET + armação de aço pode ser moldado fora do campo de obra, sem necessidade de mão de obra especializada e com possibilidade de armazenamento em local coberto, para evitar somente a corrosão da tela de aço, pois não se utiliza de nenhum material com alto poder de degradação, viabilizando a construção em comunidades de baixa renda, projetos sociais e conjuntos de obras sustentáveis.

\section{Redução de peso próprio}

Considerando as Garrafas PET utilizadas de modo tampado, tem-se a redução da utilização de concreto ou outro material de preenchimento, pois o ar ocupado dentro da garrafa, substitui tal material.

Portanto: Volume livre por garrafa $=0,002 \mathrm{~m}^{3}$

Quantidade de garrafas $/ \mathrm{m}^{2}$ de laje $=30$ unidades

Volume livre $/ \mathrm{m}^{2}$ de laje $=30 \times 0,002 \mathrm{~m}^{3}=0,06 \mathrm{~m}^{3}$

Sabendo que: Volume total da laje $/ \mathrm{m}^{2}=1 \times 0,17 \times 1=0,17 \mathrm{~m}^{3}$

Considerando a redução dos vazios das garrafas PET na laje tem-se: Volume total da laje $/ \mathrm{m}^{2}=0,11 \mathrm{~m}^{3}$

\section{Segurança}

De acordo com os testes de compressão realizados em 2 protótipos, a compressão máxima suportada por $1 \mathrm{~m}^{2}$ de laje PET é de 5712,7 kgf. Podendo ser seguramente utilizada como Laje-piso de residências.

\section{Custo}

Visto a redução de consumo de concreto em $0,06 \mathrm{~m}^{3} / \mathrm{m}^{2}$ de laje executada, considerandose a utilização de concreto usinado, $25 \mathrm{mpa}$, de acordo com Orçamento da empresa JOMANE, de Presidente Prudente, tem-se: Valor do $\mathrm{m}^{3}$ de concreto $=\mathrm{R} \$ 265,00$

Considerando a Laje sem os vazios: Valor total de concreto/m2 $=\mathrm{R} \$ 45,05$

Teria-se um custo de 45,05 reais de concreto $/ \mathrm{m}^{2}$ de laje, mas considerando a redução de $0,06 \mathrm{~m}^{3} / \mathrm{m}^{2}$ de laje devido ao uso das Garrafas PET, tem-se: Volume reduzido $/ \mathrm{m}^{2}=0,06 \mathrm{~m}^{3}=$ $\mathrm{R} \$ 15,90$.

Passando assim a ter um custo de concreto de $\mathrm{R} \$ 29,15$ por $\mathrm{m}^{2}$ de laje PET.

\section{Sustentabilidade}

De acordo com a ABIPET, no censo realizado em 2013, somente $50 \%$ das PET's consumidas no Brasil são devidamente recicladas, gerando assim o mínimo de impactos ao meio ambiente.

Pensando na Sustentabilidade da construção civil, no pensamento ecológico e no incentivo à reutilização de materiais, este método construtivo auxilia na retirada deste material com potencial poluidor do meio ambiente de modo eficaz e seguro, visto que sua utilização de modo tampada, não oferece riscos de armazenamento indevido de água e proliferação de doenças infectocontagiosas como a Dengue e o Zica vírus, transmitidos pelo mosquito Aedes Aegypti que se reproduz em águas paradas, comumente encontradas em PET abandonadas no meio ambiente.

Considerando todos os pontos positivos relacionados à cima, tal método construtivo tem características positivas relevantes para que se torne um método de construção aplicável. 


\section{REFERÊNCIAS}

ASSOCIAÇÃO BRASILEIRA DAS INDUSTRIAS PET- ABIPET-. São Paulo, s/d. Disponível em: http://www.abipet.org.br/index.html?method=mostrarlnstitucional\&id=81

ASSOCIAÇÃO BRASILEIRA DE NORMAS TÉCNICAS. NBR 6118 - Projeto de estruturas de concreto Procedimento. Rio de Janeiro, 2007.

BOTELHO, M.H.C.; MARCHETTI, O. Concreto Armado: eu te amo. São Paulo: Ed. Blucher, 2007.

CASSIMINHO, A.L.F. Modelização dos convexos representativos das fases de plasticidade em vigas de concreto armado submetidas à flexão composta desviada. Santa Maria: UFSM, 1999. Dissertação de Mestrado. Universidade Federal de Santa Maria, Santa Maria,1999.

NAPPI, S. C. B. Analise comparativa entre lajes maciças, com vigotas pré-moldadas e nervuradas. Dissertação de Mestrado. Universidade Federal de Santa Catarina, Florianópolis, 1993.

SILVA $F^{\circ}$, J. J. H. Analise experimental e numérica de laje com vigotas pré-moldadas de concreto armado. Santa Maria: UFSM, 2002. Dissertação de Mestrado. Universidade de Santa Maria, Santa Maria, 2002. 